resectron

\title{
Pancreatic inflammation and
}

\section{increased islet macrophages in} insulin-resistant juvenile primates

\author{
L E Nicol', W F Grant', S M Comstock ${ }^{2}$, M L Nguyen', M S Smith ${ }^{2}, K$ L Grove ${ }^{2}$ \\ and D L Marks ${ }^{1,3}$
}

${ }^{1}$ Pediatrics, ${ }^{2}$ Division of Neurosciences, Oregon National Primate Research Center and ${ }^{3}$ Pape Pediatric Research Institute, Oregon Health and Science University, CDRCP, 707 SW Gaines Street, Portland, Oregon 97239-3098, USA

Correspondence should be addressed to L E Nicol

Email

nicol@ohsu.edu

\begin{abstract}
Chronic high caloric intake has contributed to the increased prevalence of pediatric obesity and related morbidities. Most overweight or obese children, however, do not present with frank metabolic disease but rather insulin resistance or subclinical precursors. The innate immune system plays a role in the pathophysiology of type 2 diabetes but how it contributes to early metabolic dysfunction in children on chronic high-fat diet (HFD) is unclear. We hypothesize that such inflammation is present in the pancreas of children and is associated with early insulin resistance. We used nonhuman primate (NHP) juveniles exposed to chronic HFD as a model of early pediatric metabolic disease to demonstrate increased pancreatic inflammatory markers before the onset of significant obesity or glucose dysregulation. Pancreata from 13-month-old Japanese macaques exposed to a HFD from in utero to necropsy were analyzed for expression of cytokines and islet-associated macrophages. Parameters from an intravenous glucose tolerance test were correlated with cytokine expression. Before significant glucose dysregulation, the HFD cohort had a twofold increase in interleukin 6 (IL6), associated with decreased first-phase insulin response and a sexually dimorphic (male) increase in IL1 $\beta$ correlating with increased fasting glucose levels. The number of islet-associated macrophages was also increased. Pancreata from juvenile NHP exposed to HFD have increased inflammatory markers and evidence of innate immune infiltration before the onset of significant obesity or glucose dysregulation. Given the parallel development of metabolic disease between humans and NHPs, these findings have strong relevance to the early metabolic disease driven by a chronic HFD in children.
\end{abstract}

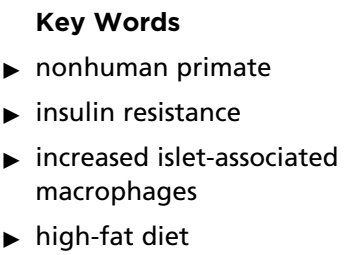

Journal of Endocrinology (2013) 217, 207-213

\section{Introduction}

Obesity is a clearly defined health problem facing the developed world, and although the causes of this epidemic are multi-factorial, a high-fat diet (HFD) is certainly a major contributor. Given that over one third of adults are obese, including women of child-bearing age (Ogden et al. 2006), exposure to a HFD for many children likely begins in utero, underscoring a very early and perhaps underappreciated chronicity to the deleterious effects of overnutrition on a developing fetus and growing child. In fact, insulin resistance, high blood pressure, hyperlipidemia, and other co-morbidities are already prevalent in overweight and obese adolescents (Rames et al. 1978, 
Freedman et al. 1999, Rosenbloom et al. 1999), and human epidemiological studies demonstrated an increased risk of type 2 diabetes and obesity-related morbidities as adults (Lauer \& Clarke 1989, Guo et al. 1994, Vanhala et al. 1998). Approaching these adult ailments in a pediatric population has left practitioners with a multitude of questions of when to medically intervene in the hope of preventing future cardiovascular complications.

Whether an overweight or obese child goes on to develop clear clinical metabolic disease as detected by standard clinical assays is multi-factorial, and there is still much to learn not only about identifying those at greatest risk but also identifying the pathophysiology at which therapy should be targeted. Indeed, the definition and medical treatment of metabolic disease in pediatrics employs many adult characterizations and drugs designed in adult clinical trials, yet it is the precursors of the disease and potential yet-to-be defined parameters that are more pertinent for children. Greater insight is needed in understanding the initial pathophysiology associated with early and chronic exposure to HFD in children and how this contributes to the risk of developing metabolic disease.

One component relevant to early metabolic pathophysiology is peripheral tissue inflammation driven by innate immune responses to longstanding exposure to gluco- and lipotoxicity. Such chronic and ongoing insults manifesting as auto-inflammation are now recognized as part of obesity-related metabolic disease and are associated with insulin resistance and type 2 diabetes (Pickup et al. 1997, Xu et al. 2003). A prospective study in humans identified the presence of specific systemic acute-phase proteins as predictive of the development of type 2 diabetes in adults (Spranger et al. 2003). Yet for obvious reasons, the analysis of early inflammatory markers either systemically or within specific tissue of children exposed to chronic toxicities such as a HFD is not readily available. This is especially true regarding data for those populations of children who have not yet manifested significant obesity or glucose dysregulation. Thus, as a result of fetal and early childhood exposure to HFD, we hypothesized that markers of inflammation appear early in the pancreas and pancreatic islets, at a stage before onset of severe insulin resistance or type 2 diabetes, and that their levels would be correlated with early subclinical parameters of abnormal glucose homeostasis.

We used the nonhuman primate (NHP) model, which, because of its close relationship to human development and the pathophysiology of type 2 diabetes ( $\mathrm{O}^{\prime}$ Brien et al. 1996), has multiple advantages in studying metabolic disease and the effects of pre- and postnatal HFD exposures. This is particularly true with regard to islet expansion and islet cyto-architecture (Cabrera et al. 2006, Bosco et al. 2010). Additionally, fetal nutrition and development are parallel to those in humans including mostly singleton pregnancies, parallel duration of gestation, and similar placental structures (Carter 2007). Previous studies of NHP fetal and juvenile offspring exposed to prenatal and postweaning HFD have demonstrated a multitude of metabolic abnormalities including fetal liver lipotoxicity, alterations in the serotonergic system, increased inflammatory pathways, abnormal endothelial function, and alterations in pancreatic islet development (McCurdy et al. 2009, Grayson et al. 2010, Sullivan et al. 2010, Comstock et al. 2011, Fan et al. 2012), clearly establishing the effects of a HFD on the development of multiple systems within this model. Our objective was to demonstrate evidence of inflammation in the pancreas to further elucidate the implications of a chronic HFD on this tissue and development of early insulin resistance.

\section{Materials and methods}

\section{Animal model}

Animal procedures were carried out within guidelines of the Institutional Animal Care and Use Committee of the Oregon National Primate Center (ONPRC) and as have been previously described in detail (Grant et al. 2011). Briefly, age- and weight-matched adult female Japanese macaques (Macaca fuscata) were placed on a normal (13\% of calories from fat) or HFD (35.2\% calories from fat) including calorically dense treats. Diet composition was previously analyzed and described in detail (Grant et al. 2011). Animals were group-housed and given ad libitum access to food and water. Offspring were born naturally, stayed with their mothers until weaning ( $\sim 8$ months), and the cohort of offspring included in this study were continued on their respective diet until necropsy at $\sim 13$ months of age.

\section{Glucose tolerance testing}

One week before necropsy, fasting juvenile offspring underwent a sedated intravenous glucose tolerance test (IVGTT) using $0.6 \mathrm{~g} / \mathrm{kg}$ glucose. Baseline and timed samples of glucose and insulin were obtained as described previously and reviewed in detail (Comstock et al. 2011, Grant et al. 2011). Areas under the curve for glucose and insulin response were calculated. First-phase insulin response was measured as the difference between baseline

Published by Bioscientifica Ltd 
and peak insulin within the first $10 \mathrm{~min}$ of glucose infusion (Comstock et al. 2011).

\section{Cytokine expression and M1 and M2 markers}

Total pancreas RNA was extracted using TRIzol from five head to tail grouped sections of each offspring, DNase treated, and reverse transcribed. Quantitative PCR including disassociation curves was run on the Applied Biosystems 7300 using SYBR master mix and primer concentrations of $471 \mathrm{nM}$ in $21 \mu \mathrm{l}$ reactions. Alg9 was the endogenous control for all targets and has been previously validated in primate tissue (Grant et al. 2011). Primer sequences used for RT-PCR were previously verified by sequencing and were demonstrated to have high efficiency (Grant et al. 2011). Relative expression of each gene was calculated as $2^{(-\Delta \Delta C t)}$.

Commercially available TaqMan probes were used to identify expression of inducible nitric oxide synthase (iNOS; Rh02829284_m1) and Arginase (Arg1; Rh02826373_m1) M1- and M2-activated macrophages respectively from the same cDNA as mentioned earlier. Quantitative PCRs were run on an ABI 7300 (Applied Biosystems), using TaqMan universal PCR master mix TaqMan master mix in a $10 \mu$ l reaction.

\section{Islet-associated macrophages}

Slides of fixed and paraffin-embedded tissue at 5-6 $\mu \mathrm{m}$ sections were incubated with monoclonal mouse anti-human CD68 (Dako, Carpinteria, CA, USA) at 1:100 overnight at $4{ }^{\circ} \mathrm{C}$ using the Vectastain $\mathrm{ABC}$ Elite (\#PK-4002, Vector, Burlingame, CA, USA) and DAB (\#SK-4105) kits followed by rabbit insulin polyclonal antibodies (\#20056, Immunostar, Hudson, WI, USA) at 1:1000 overnight at $4{ }^{\circ} \mathrm{C}$ using Vectastain ABC-AP (\#AK5001) and Vector Red (\#SK-5100) kits. Non-overlapping digital images were obtained using Leica DFC340FX Microscope and Leica Application Suite v3.0 at $40 \times$ under bright-field optics by an observer blinded to the sample identity and subsequently decoded for the statistical analysis. Every islet with $>10$ nuclei was counted within each field. An islet-associated macrophage was identified as a CD68 + cell in contact with an insulin-positive cell, and liver was used at the positive control. Macrophage data are reported as the total number of CD68 + cells divided by the total islet area (quantified by Image J). Thirty to 45 islets were counted from three sections for each animal. TUNEL assay for markers of apoptosis was carried out using the ApopTag Plus Peroxidase In Situ Apoptosis Kit (\#S7101 Millipore, Temecula, CA, USA).

\section{Amyloid staining}

Pancreatic sections were fixed and embedded as mentioned earlier and stained using Amyloid Stain, Congo Red Kit Congo Red (\#HT60-1KT Sigma), as per manufacturer's protocol, and commercially available human cardiac tissue, Amyloid Tissue-TROL (A2424-25EA, Sigma), was used as the positive control. Exocrine and endocrine tissue from three sections of each animal was examined under bright-field at $20 \times$ using the same scope Leica DFC340FX Microscope as mentioned earlier.

\section{Statistical analysis}

Two-tailed $t$-tests and linear regression analysis were used on the $\Delta C \mathrm{t}$ of gene expression and the islet-associated macrophage counts between the treatment groups and reported as means \pm s.E.M. Variances (data not shown) between the two treatment groups did not differ significantly except for the analysis of interleukin $1 \beta$ (IL1 $\beta$ ) in which the male HFD cohort had significantly elevated expression. For analysis of IL1 $\beta$, the Mann-Whitney $U$ test was used when both sexes were grouped together to adjust for the non-equal variance. Statistical significance was defined at $P<0.05$.

\section{Results}

\section{Metabolic phenotype}

As previously reported, the chronic HFD juvenile monkeys did not have significant changes in glucose levels but they did demonstrate alterations in insulin regulation reflective of insulin resistance. IVGTT parameters showed that fasting insulin was two times higher, insulin area under the curve (AUC) was 1.5 times higher, and homeostatic model assessment - insulin resistance (HOMA-IR) was over two and a half times higher vs their controls (Comstock et al. 2011, Fan et al. 2012). Fasting glucose values were normal and there were no differences in free fatty acid or triglyceride levels or bodyweight at the time of the necropsy (Comstock et al. 2011, Fan et al. 2012). The dams were sensitive to the HFD with significantly elevated body weights compared with age-matched controls as previously reported (McCurdy et al. 2009).

\section{Inflammatory cytokines and macrophage M1 and M2 markers}

The cytokines analyzed included IL6, TNF $\alpha$, CRP, IL1 $\beta$, MCP-1, and IL10 and were chosen based on their

Published by Bioscientifica Ltd. 
(a)

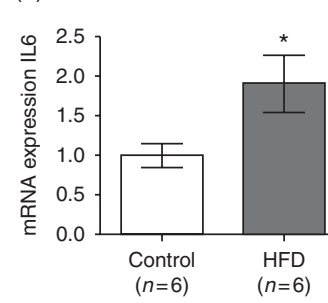

(b)

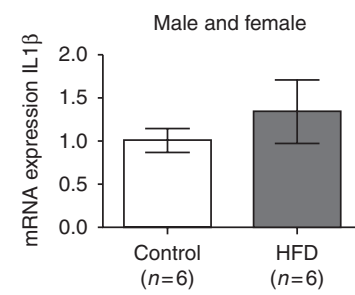

(c)

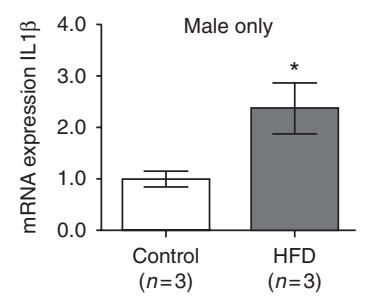

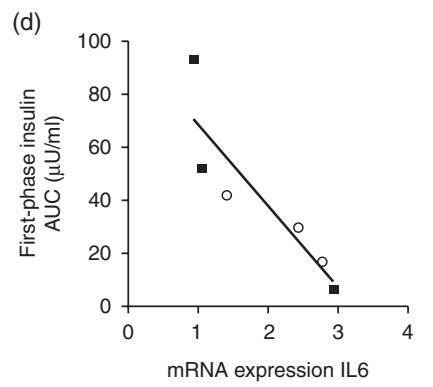

mRNA expression IL6

(e)

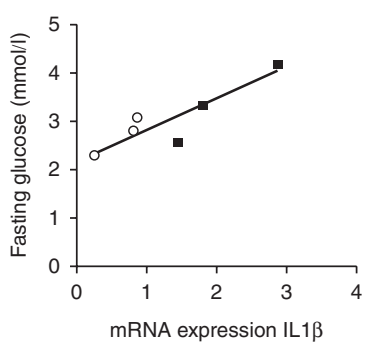

\section{Figure 1}

The HFD cohort has a $1.9( \pm 0.4)$-fold increase in the relative expression of IL6 compared with controls $(1.0( \pm 0.1)$; a). Relative expression IL $1 \beta$ is not significantly elevated when males and females are grouped (b) but is increased 2.4 ( \pm 0.5 )-fold in the male HFD compared with male controls $(1.0( \pm 0.2) ; C)$. As the levels of IL6 increase, first-phase insulin decreases in

association with obesity-related inflammation. IL6 was significantly increased in the HFD pancreas (Fig. 1a; $P<0.05$; control $\Delta C \mathrm{t} 10.7( \pm 0.2)$; HFD $\Delta C \mathrm{t} 9.8( \pm 0.3))$ and was strongly correlated with a decrease in first-phase insulin response (Fig. 1d). IL1 $\beta$ was not significantly increased when both sexes were analyzed together (Fig. 1b) but was significant $(P<0.05)$ in males alone (Fig. 1c; controls $\Delta C \mathrm{Ct} 7.8( \pm 0.2) n=3 ; \Delta C \mathrm{t}$ HFD $6.6( \pm 0.3)$ $n=3$ ) and correlated with increased fasting blood glucose in both males and females (Fig. 1e). The mean relative expression of TNF $\alpha, \mathrm{CRP}$, and IL10 compared to controls were consistently higher in the HFD group but analysis of the $\Delta C t$ values did not reach statistical significance (Fig. 2). IL6 did not correlate with fasting glucose nor did IL1 $\beta$ correlate with first-phase insulin response. There was no change in the expression levels of either iNOS, an M1 macrophage marker, or Arg1, an M2 macrophage marker, between treatment groups.

\section{Histology}

The number of islet-associated macrophages detected by the CD68 antibody and normalized to total islet was significantly increased in the HFD group (Fig. 3). Most both females (open circles) and males (closed squares) $\left(R^{2}=0.83, P<0.05\right.$; d) and as IL1 $\beta$ increases so do fasting glucose levels $\left(R^{2}=0.66, P<0.05\right)$ that are still within the normal range (e). For all graphs, relative expression is potted but all statistical analysis is done on the $\Delta C$ t values. ${ }^{*}$ indicates $P$ value $<0.05$.

macrophages identified were located within the vascular planes or along the periphery of the islet.

There were no changes in the number of apoptotic cells within the islets of HFD juveniles $(n=6)$ vs controls
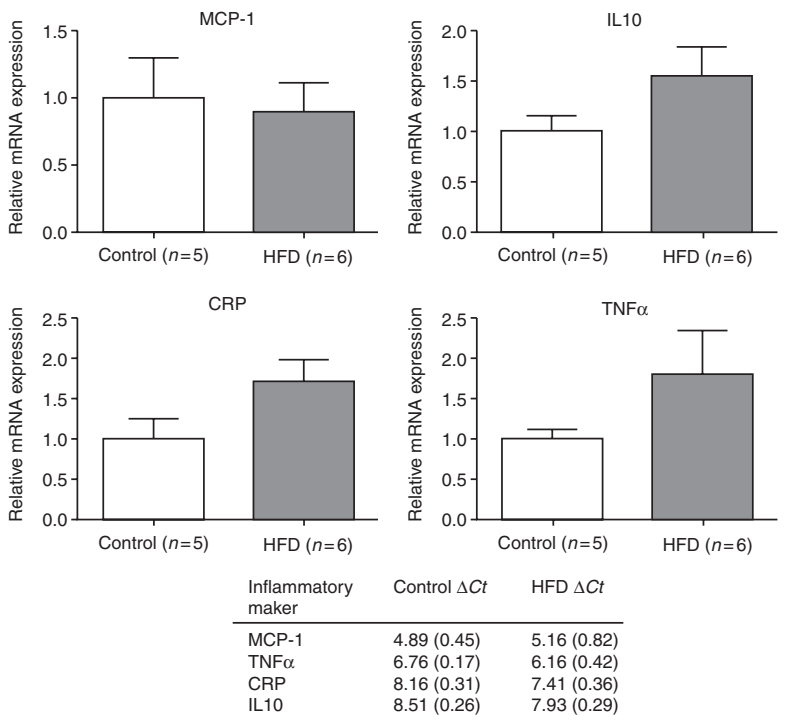

Figure 2

The relative expression and $\Delta C t$ values of other cytokines analyzed.

Published by Bioscientifica Ltd 
(a)

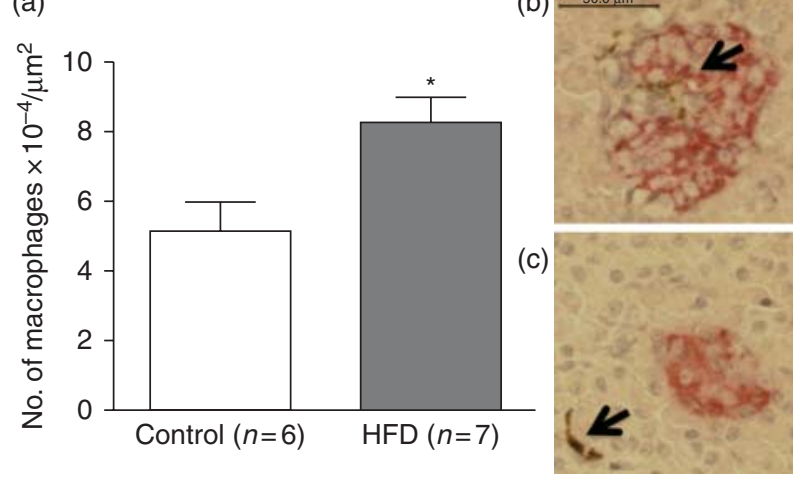

Figure 3

Macrophage number per islet area is increased in the HFD cohort $(P<0.05$, control $5.1( \pm 0.8)$; HFD $8.3( \pm 0.7) \times 10^{-4} / \mu \mathrm{m}^{2} ;$ a). Insulin producing $\beta$ cell (red) demarcates the islet and $\mathrm{CD} 68^{+}$macrophages (brown) are indicated by the black arrow demonstrating the increased islet-associated macrophages in the HFD juveniles (b) vs control juveniles (c). *indicates $P$ value $<0.05$.

$(n=7)$ (data not shown). Over 150 islets were scanned for cells positive for the TUNEL marker in each animal and 0-3 events were identified. Statistical analysis was not performed, as positive cells were deemed too rare in either group to have a clinical significance. Mouse mammary tissue was used as the TUNEL assay control and stained positively (data not shown).

There was no identifiable staining for amyloid deposits in either the control or the HFD primates. Human cardiac tissue was used as positive control and stained robustly (data not shown).

\section{Discussion}

The NHP among all other animal models provides the greatest insight into human metabolic disease and provides an otherwise impossible window into the early changes occurring in children exposed to a chronic HFD. This study uses a well-established model of juvenile primates exposed to maternal and postnatal overnutrition that has already demonstrated deleterious changes in behavior, cardiovascular abnormalities, hepatic toxicity, and alterations in their islet development. Here, we established the inflammatory profile of the pancreas with the unique opportunity of correlating these findings directly to the metabolic phenotype.

Analysis of the inflammatory markers and isletassociated macrophages in these juvenile monkeys revealed that markers of inflammation are present in the pancreas of offspring exposed to chronic HFD with early insulin resistance. Such findings elucidate a process in this tissue preceding both the onset of significant metabolic disease or obesity and the onset of increased $\beta$-cell apoptosis or amyloid deposition. Previous studies describe increased inflammation in pancreas and islets of humans with type 2 diabetes (Ehses et al. 2007), but to our knowledge, this is the first time such findings have been identified in the early stages of insulin resistance outside of rodent models of diabetes (Homo-Delarche et al. 2006, Ehses et al. 2007). In fact, it should be noted that there were no differences in the body weight of these animals, thus suggesting that the development of the early metabolic and inflammatory changes does not require the onset of clinical obesity. Because of the parallels of metabolic disease development between primates and humans, these data imply that inflammation is occurring within the pancreatic tissue of children chronically exposed to a western HFD well before the clinical diagnosis of glucose intolerance or 'pre-diabetes' or even significant obesity.

The mild inflammatory profile seen in the HFD cohort is expected as their metabolic abnormalities are also at an early stage. It is interesting to note, however, that IL6 was the predominant cytokine elevated and correlated strongly with a decrease in first-phase insulin response, suggesting a role for this cytokine in early $\beta$-cell dysfunction. Although our study did not address isletspecific cytokine levels, regardless of an exocrine or endocrine source, the rodent islet has proven to be affected by the presence of cytokines as these micro-organs express several cytokine receptors including IL6 (Ellingsgaard et al. 2008). These findings are consistent with and supported by previous studies from rodent islets demonstrating impaired insulin release with IL6 treatment (Southern et al. 1990) and work identifying a predictive value of systemic IL6 for the development of type 2 diabetes in clinical studies in humans (Pradhan et al. 2001, Spranger et al. 2003). The true role of IL6 on islet function is still debated as rodent studies demonstrated both beneficial and deleterious effects on insulin secretion and its role in human islets needs further exploration (Kristiansen \& Mandrup-Poulsen 2005, Ellingsgaard et al. 2008).

IL1 $\beta$ had a large variability of expression that was accounted for by sex. While IL1 $\beta$ was not statistically elevated in the HFD cohort as a whole, it was increased in males alone. Islets, most abundantly in the insulin secreting $\beta$ cells, express IL1 receptors allowing for a mechanism of action within the endocrine tissue (Boni-Schnetzler et al. 2009). Given the small sample size, this finding is preliminary but corresponds to the

Published by Bioscientifica Ltd 
greater vulnerability of males in developing type 2 diabetes and is consistent with other sexually dimorphic results within this NHP HFD model, including increased adiposity and fasting glucose (Comstock et al. 2011). Additionally, previously published data from this model have also demonstrated inflammatory changes in other tissues and organs including endothelial tissue and fetal and adult liver, suggesting a global insult of the HFD (McCurdy et al. 2009, Grant et al. 2011, Fan et al. 2012).

Like IL6, IL1 $\beta$ expression also correlated with abnormalities of glucose homeostasis in both males and females demonstrated by increasing levels of gene expression with increasing fasting glucose levels. This is consistent with the findings from human islets and $\beta$-cell studies from type 2 diabetics (Boni-Schnetzler et al. 2008), but our data further demonstrate elevation of this cytokine while blood glucose is still within the normal range, before clinical disease.

A key finding from the HFD cohort is the increase in islet-associated macrophages. The presence of macrophages and other immune cells associated with islets has been described in humans and animal models of type 2 diabetes (Homo-Delarche et al. 2006, Ehses et al. 2007), but this is the first demonstration that macrophage infiltration is significantly increased as part of early insulin resistance physiology in primates. The mechanism and cell signaling resulting in the increased presence of innate immune cells requires further delineation. Differentiating the type of macrophage using just iNOS and Arg1 did not reveal a particular polarity of activation, however, considering that the elevated markers overall were proinflammatory (IL1 $\beta$ and IL6) and the markers Arg1 and IL10 (M2 associated) were not significantly increased suggests skewing towards an M1 profile. Regardless, their increase in number before the onset of type- 2 diabetes or even glucose intolerance may indicate an early role in the pathogenesis of glucose dysregulation associated with chronic HFD exposure.

Longitudinal studies of obese children demonstrated defects in insulin sensitivity and secretion before the onset of glucose dysregulation as measured by hyperinsulinemic-euglycemic clamp studies and mathematical models (Giannini et al. 2012). These data highlight how early deleterious changes are detected in children without overt clinical disease and thus would not otherwise be picked up by standard clinical assays. Such changes in insulin sensitively and secretion in the pediatric population requires a broader understanding of the mechanism and pathology altering these pathways. Our data add to the growing body of research describing the physiology behind such subclinical changes in children as a result of chronic HFD exposure using a surrogate but closely related NHP model. This is an important step toward defining how best to treat and intervene with the hopes of reversing or significantly delaying the onset of serious conditions such as type 2 diabetes.

\section{Declaration of interest}

The authors declare that there is no conflict of interest that could be perceived as prejudicing the impartiality of the research reported.

\section{Funding}

This research was made possible by the Child Health Research Center Grant (K12HD057588), The Impact of Maternal Health and Diet on Development of Fetal Metabolic Systems (5R24DK090964) grant, and the Burroughs Wellcome Fund (1007518).

\section{Author contribution statement}

$L E N, W R G, K L G$, and $D L M$ are responsible for conception and design of the research; LE N and M L N performed the experiments; L E N and D L M analyzed the data and drafted and approved the final manuscript; and all authors interpreted the results of the experiments and edited the manuscript.

\section{Acknowledgements}

The authors would like to thank both Diana Takahashi for coordinating access to primate tissue and Barbara Mason for her expertise in tissue histology from the Oregon National Primate Research Center. Michael Lasarev provided assistance with statistical analysis at Oregon Health and Science University (OHSU). A special thanks to Ted Braun, Stephanie Krasnow, Peter Levasseur, and Xinxia Zhu for their research advice and expertise (OHSU).

\section{References}

Boni-Schnetzler M, Thorne J, Parnaud G, Marselli L, Ehses JA, Kerr-Conte J, Pattou F, Halban PA, Weir GC \& Donath MY 2008 Increased interleukin (IL)-1 $\beta$ messenger ribonucleic acid expression in $\beta$-cells of individuals with type 2 diabetes and regulation of IL-1 $\beta$ in human islets by glucose and autostimulation. Journal of Clinical Endocrinology and Metabolism 93 4065-4074. (doi:10.1210/jc.2008-0396)

Boni-Schnetzler M, Boller S, Debray S, Bouzakri K, Meier DT, Prazak R, Kerr-Conte J, Pattou F, Ehses JA, Schuit FC et al. 2009 Free fatty acids induce a proinflammatory response in islets via the abundantly expressed interleukin-1 receptor I. Endocrinology 150 5218-5229. (doi:10.1210/en.2009-0543)

Bosco D, Armanet M, Morel P, Niclauss N, Sgroi A, Muller YD, Giovannoni L, Parnaud G \& Berney T 2010 Unique arrangement of $\alpha$ - and $\beta$-cells in human islets of Langerhans. Diabetes 59 1202-1210. (doi:10.2337/ db09-1177)

Cabrera O, Berman DM, Kenyon NS, Ricordi C, Berggren PO \& Caicedo A 2006 The unique cytoarchitecture of human pancreatic islets has implications for islet cell function. PNAS 103 2334-2339. (doi:10.1073/ pnas.0510790103) 
Carter AM 2007 Animal models of human placentation - a review. Placenta 28 S41-S47. (doi:10.1016/j.placenta.2006.11.002)

Comstock SM, Bishop JM, Takahashi DL, Cornea AN, Smith MS \& Grove KL 2011 High-fat diet during early development elicits $\beta$-cell expansion and an increase in the $\beta$-cell/ $\alpha$-cell ratio in the juvenile nonhuman primate. Endocrine Reviews 32 (03_Meeting Abstracts) OR01-OR03.

Ehses JA, Perren A, Eppler E, Ribaux P, Pospisilik JA, Maor-Cahn R, Gueripel X, Ellingsgaard H, Schneider MK, Biollaz G et al. 2007 Increased number of islet-associated macrophages in type 2 diabetes. Diabetes 56 2356-2370. (doi:10.2337/db06-1650)

Ellingsgaard H, Ehses JA, Hammar EB, Van Lommel L, Quintens R, Martens G, Kerr-Conte J, Pattou F, Berney T, Pipeleers D et al. 2008 Interleukin-6 regulates pancreatic $\alpha$-cell mass expansion. PNAS 105 13163-13168. (doi:10.1073/pnas.0801059105)

Fan L, Lindsley SR, Comstock SM, Takahashi DL, Evans AE, He GW, Thornburg KL \& Grove KL 2012 Maternal high-fat diet impacts endothelial function in nonhuman primate offspring. International Journal of Obesity 37 254-262. (doi:10.1038/ijo.2012.42)

Freedman DS, Dietz WH, Srinivasan SR \& Berenson GS 1999 The relation of overweight to cardiovascular risk factors among children and adolescents: the Bogalusa Heart Study. Pediatrics 103 1175-1182. (doi:10.1542/peds.103.6.1175)

Giannini C, Weiss R, Cali A, Bonadonna R, Santoro N, Pierpont B, Shaw M \& Caprio S 2012 Evidence for early defects in insulin sensitivity and secretion before the onset of glucose dysregulation in obese youths: a longitudinal study. Diabetes 61 606-614. (doi:10.2337/db11-1111)

Grant WF, Gillingham MB, Batra AK, Fewkes NM, Comstock SM, Takahashi D, Braun TP, Grove KL, Friedman JE \& Marks DL 2011 Maternal high fat diet is associated with decreased plasma $n-3$ fatty acids and fetal hepatic apoptosis in nonhuman primates. PLOS ONE 6 e17261. (doi:10.1371/journal.pone.0017261)

Grayson BE, Levasseur PR, Williams SM, Smith MS, Marks DL \& Grove KL 2010 Changes in melanocortin expression and inflammatory pathways in fetal offspring of nonhuman primates fed a high-fat diet. Endocrinology 151 1622-1632. (doi:10.1210/en.2009-1019)

Guo SS, Roche AF, Chumlea WC, Gardner JD \& Siervogel RM 1994 The predictive value of childhood body mass index values for overweight at age $35 \mathrm{y}$. American Journal of Clinical Nutrition 59 810-819.

Homo-Delarche F, Calderari S, Irminger JC, Gangnerau MN, Coulaud J, Rickenbach K, Dolz M, Halban P, Portha B \& Serradas P 2006 Islet inflammation and fibrosis in a spontaneous model of type 2 diabetes, the GK rat. Diabetes 55 1625-1633. (doi:10.2337/db05-1526)

Kristiansen OP \& Mandrup-Poulsen T 2005 Interleukin-6 and diabetes: the good, the bad, or the indifferent? Diabetes $\mathbf{5 4}$ (Suppl 2) S114-S124. (doi:10.2337/diabetes.54.suppl_2.S114)

Lauer RM \& Clarke WR 1989 Childhood risk factors for high adult blood pressure: the Muscatine Study. Pediatrics 84 633-641.

McCurdy CE, Bishop JM, Williams SM, Grayson BE, Smith MS, Friedman JE \& Grove KL 2009 Maternal high-fat diet triggers lipotoxicity in the fetal livers of nonhuman primates. Journal of Clinical Investigation 119 323-335. (doi:10.1172/JCI32661)

O'Brien TD, Wagner JD, Litwak KN, Carlson CS, Cefalu WT, Jordan K, Johnson KH \& Butler PC 1996 Islet amyloid and islet amyloid polypeptide in cynomolgus macaques (Macaca fascicularis): an animal model of human non-insulin-dependent diabetes mellitus. Veterinary Pathology 33 479-485. (doi:10.1177/030098589603300501)

Ogden CL, Carroll MD, Curtin LR, McDowell MA, Tabak CJ \& Flegal KM 2006 Prevalence of overweight and obesity in the United States, 1999-2004. Journal of the American Medical Association 295 1549-1555. (doi:10.1001/jama.295.13.1549)

Pickup JC, Mattock MB, Chusney GD \& Burt D 1997 NIDDM as a disease of the innate immune system: association of acute-phase reactants and interleukin-6 with metabolic syndrome X. Diabetologia 40 1286-1292. (doi:10.1007/s001250050822)

Pradhan AD, Manson JE, Rifai N, Buring JE \& Ridker PM 2001 C-reactive protein, interleukin 6 , and risk of developing type 2 diabetes mellitus. Journal of the American Medical Association 286 327-334. (doi:10.1001/ jama.286.3.327)

Rames LK, Clarke WR, Connor WE, Reiter MA \& Lauer RM 1978 Normal blood pressure and the evaluation of sustained blood pressure elevation in childhood: the Muscatine Study. Pediatrics 61 245-251.

Rosenbloom AL, Joe JR, Young RS \& Winter WE 1999 Emerging epidemic of type 2 diabetes in youth. Diabetes Care 22 345-354. (doi:10.2337/ diacare.22.2.345)

Southern C, Schulster D \& Green IC 1990 Inhibition of insulin secretion from rat islets of Langerhans by interleukin-6. An effect distinct from that of interleukin-1. Biochemical Journal 272 243-245.

Spranger J, Kroke A, Mohlig M, Hoffmann K, Bergmann MM, Ristow M, Boeing H \& Pfeiffer AF 2003 Inflammatory cytokines and the risk to develop type 2 diabetes: results of the prospective population-based European Prospective Investigation into Cancer and Nutrition (EPIC)-Potsdam Study. Diabetes 52 812-817. (doi:10.2337/diabetes.52. 3.812)

Sullivan EL, Grayson B, Takahashi D, Robertson N, Maier A, Bethea CL, Smith MS, Coleman K \& Grove KL 2010 Chronic consumption of a high-fat diet during pregnancy causes perturbations in the serotonergic system and increased anxiety-like behavior in nonhuman primate offspring. Journal of Neuroscience 30 3826-3830. (doi:10.1523/ JNEUROSCI.5560-09.2010)

Vanhala M, Vanhala P, Kumpusalo E, Halonen P \& Takala J 1998 Relation between obesity from childhood to adulthood and the metabolic syndrome: population based study. BMJ 317 319. (doi:10.1136/ bmj.317.7154.319)

Xu H, Barnes GT, Yang Q, Tan G, Yang D, Chou CJ, Sole J, Nichols A, Ross JS, Tartaglia LA et al. 2003 Chronic inflammation in fat plays a crucial role in the development of obesity-related insulin resistance. Journal of Clinical Investigation 112 1821-1830.

Received in final form 13 February 2013

Accepted 18 February 2013

Accepted Preprint published online 18 February 2013 http://joe.endocrinology-journals.org DOI: 10.1530/JOE-12-0424
() 2013 Society for Endocrinology Printed in Great Britain
Published by Bioscientifica Ltd. 